\title{
Comparison of Fissure Healing and The Incidence of Headache Among the Patients Treated with Endo- and Perianal Application of $0.2 \%$ Glyceryl Trinitrate for Chronic Anal Fissure
}

\author{
Mukund Raj Joshi,, Tanka Prasad Bohara, ${ }^{1}$ Shail Rupakheti ${ }^{1}$ \\ 'Department of Surgery, Kathmandu Medical College Sinamangal, Kathmandu, Nepal.
}

\section{ABSTRACT}

Introduction: Chronic anal fissure is associated with significant morbidity and reduction in quality of life mostly in young healthy adults. Glyceryl Trinitrate, a most commonly used agent for treatment, is associated with incidence of headache causing discontinuation of treatment. There is belief that endoanal application instead of perianal is associated with lower incidence of headache. This study is to compare the incidence and severity of headache in between perianal and endoanal application of GTN ointment.

Methods: Thirty patients were taken in each perianal and endoanal group. They were given orientation to apply $375 \mathrm{gm}$ of ointment either endoanally or perianally and to record severity of headache according to visual analogue scale. This record was noted by independent observer in telephonic conversation. Patients were followed up at 6 weeks for evaluation fissure.

Results: The mean age, male female ratio and features of chronicity was similar in both the group however the duration of symptoms between the group was different. Regarding outcome, Overall incidence of headache was seen in two-third of patient with severe headache in approx. $10 \%$. Severity of headache was slightly lower in endoanal group but the difference was not significant. Healing rate was comparable. Two patient in perianal and 3 in endoanal group were lost for follow up.

Conclusions: Endoanal application of GTN ointment is associated with slight decrease in intensity of headache and is comparable with perianal application for fissure healing.

Keywords: anal fissure; endoanal; glyceryl trinitrate; headache; perianal.

\section{INTRODUCTION}

Anal fissure is a linear mucosal tear in the anal canal below dentate line, usually in posterior midline which causes pain during defecation lasting for one or two hours reducing the quality of life and causing morbidity..$^{1-3}$ The most consistent feature of anal fissure is severe spasm of internal anal sphincter leading to ischaemia that causes pain. ${ }^{4}$ The methods to relieve spasm either surgical or chemical is associated with relief of pain and healing of the fissure. Complications associated with surgery has induced the enthusiasm for the use of Topical agents in chronic anal fissure..$^{5,6}$

Topical Glyceryl trinitrate (GTN) is most commonly used agent which causes transient relaxation of internal anal sphincter promoting healing of the fissure by providing exogenous nitrous oxide. ${ }^{7,8}$ Headache is the major side

Correspondence: Dr. Mukund Raj Joshi, Department of Surgery, Kathmandu Medical College, Baburam Acharya Sadak, Sinamangal, Kathmandu, Nepal. Email: mukundraijoshi@gmail.com, Phone: +977. 98519008493 . 
effect of GTN therapy, leading discontinuation of the treatment. ${ }^{9}$ A solution to this have been proposed by Torrabadella and Salgado in a pilot study showing endoanal application instead of perianal has lower incidence of headache with comparable result of healing. ${ }^{10}$

In this study, we compare the perianal and endoanal application methods in regards to fissure healing and incidence of headache.

\section{METHODS}

A prospective comparative study was conducted in Department of Surgery, Kathmandu Medical College from April 2015 and September 2015. Ethical Approval and patient consent was taken. All the patients attending surgical outpatient clinic of our institute with the features of chronic anal fissures were enrolled for the study and informed consent was taken. Every alternate patient was grouped in either perianal or endoanal group. Demographics were recorded. Patient's cellphone number was noted.

Patients were educated to apply the $0.2 \%$ Nitroglycerine ointment as described below according the group they belong. They were taught and asked to keep a diary to note the incidence and severity of the headache after each application and grade the severity of headache in Visual analogue scale (VAS) of 0-10. Zero indicating no headache and 10 indicating maximum imaginable headache for one week. From day of starting the treatment, up to 7days they were called daily at a particular time in their cell number by either medical attendant or junior doctor who is not involved in study and does not know the group of patient. They were enquired about the severity of headache in VAS. The subjects who develop intolerable headache during this period were asked to discontinue the treatment and advised to choose surgical option. Those who can tolerate the headache were asked to continue the treatment and follow up at the end of 6 week for the evaluation of fissure wound and response of the treatment. None of the patients were asked to switch to another modality of therapy. The patients who were unable to follow the protocol, unwilling to be the part of study and those who did not communicate for first 7 days of therapy were not included in the study.

For perianal group patient, they were asked to squeeze the $2.5 \mathrm{~cm}$ (approx. one finger breadth) of $0.2 \%$ GTN ointment tube (Nitrogesic ${ }^{\circledR}$ ) (approx. 375gm preparation) in their fingertip and apply the preparation around affected area.

For Endoanal group patient, they were asked to replace the tube cap with long tip applicator and introduce into the anal canal and squeeze $2.5 \mathrm{~cm}$ (approx. one finger breadth) of $0.2 \%$ GTN ointment tube (approx. $375 \mathrm{gm}$ preparation).

The collected data was compiled in SPSS 20 table and analyzed using student's t test, Chi-square test, Fisher's exact test and one -way ANOVA where-ever was appropriate.

\section{RESULTS}

Total 60 patients were enrolled. Thirty in Perianal (Group 1) and 30 in Endoanal group. There is no difference of mean age, gender distribution, features of chronicity in both the groups. But there is significant difference in mean duration of symptoms between the groups (Table 1).

\begin{tabular}{|c|c|c|c|c|}
\hline Patient variables & & $\begin{array}{l}\text { Perianal } \\
(\mathrm{n}=30)\end{array}$ & $\begin{array}{l}\text { Endoanal } \\
(\mathrm{n}=30)\end{array}$ & P-value \\
\hline Age in years (Mean \pm SD) & & $40.02 \pm 13.23$ & $37.23 \pm 9.61$ & 0.691 \\
\hline $\begin{array}{l}\text { Duration of symptoms in Weeks } \\
\text { (Mean } \pm \text { SD) }\end{array}$ & & $45.57 \pm 66.32$ & $17.57 \pm 12.687$ & 0.027 \\
\hline \multirow{2}{*}{ Sex } & Male & $15(50 \%)$ & $8(26.7 \%)$ & \multirow{2}{*}{0.063.} \\
\hline & Female & $15(50 \%)$ & $22(73.3 \%)$ & \\
\hline \multirow[t]{4}{*}{ Features of chronicity } & Sentinel tag & $15(50 \%)$ & $16(53.3 \%)$ & \multirow{4}{*}{0.722} \\
\hline & Heaped up margin & $12(40 \%)$ & $9(30 \%)$ & \\
\hline & Fibres on the base. & $2(6.7 \%)$ & $2(6.7 \%)$ & \\
\hline & Endoanal polyp & $1(3.3 \%)$ & $3(10 \%)$ & \\
\hline
\end{tabular}

$S D=$ Standard Deviation 
After the treatment was started, outcome variable in regards to the severity of headache within 7 days, healing at the end of 6 weeks and final outcome of the patient is shown in table 2. Severity of headache according to the VAS is classified into no headache for 0 score, Mild headache for score 1-3, Moderate headache for score 4-6 and Severe headache for score 7-10. There was $100 \%$ follow up for 7 days but at the end of study i.e. at 6 weeks, two patient in perianal and 3 patient in endoanal group did not come for follow up. Approximately $2 / 3$ of patient suffered with varying intensity of headache. But the majority of these were mild to moderate. Healing at the end of 6 weeks and overall patient outcome is comparable in both group. Regarding headache (Table 3 ), There is less intensity of mean score of headache (3.3 Vs 2.57) in endoanal group in comparison to perianal. Intensity of headache during 7 days is compared in between the group and within the group. Test did not show statistical difference.

\begin{tabular}{|c|c|c|c|c|}
\hline Outcome variables & & $\begin{array}{l}\text { Perianal } \\
(n=30)\end{array}$ & $\begin{array}{l}\text { Endoanal } \\
(\mathrm{n}=30)\end{array}$ & P-value \\
\hline \multirow[t]{4}{*}{ Healing of fissure. } & Complete healing & $13(43.3 \%)$ & $9(30 \%)$ & \multirow{8}{*}{0.557} \\
\hline & Partial healing & $8(26.7 \%)$ & $13(43.3 \%)$ & \\
\hline & No healing & $7(23.3 \%)$ & $6(20 \%)$ & \\
\hline & Abandoned/stopped/FU lost & $2(6.7 \%)$ & $2(6.6 \%)$ & \\
\hline \multirow[t]{4}{*}{ Severity of Headache } & No headache (score 0) & $7 \quad(23.7 \%)$ & $8(26.7 \%)$ & \\
\hline & Mild Headache (Score 1-3) & $7 \quad(23.3 \%)$ & $14(46.7 \%)$ & \\
\hline & Moderate Headache (score 4-6) & $13(43.3 \%)$ & $6(20.0)$ & \\
\hline & Severe headache (Score $>7$ ) & $3(10 \%)$ & $2(6.7 \%)$ & \\
\hline \multirow[t]{4}{*}{ Outcome of patient } & Treatment complete & $13(43.3 \%)$ & $9(30 \%)$ & \multirow{4}{*}{0.487} \\
\hline & Treatment repeated & $8(26.7 \%)$ & $13(43.3 \%)$ & \\
\hline & Switched to Surgery & $7(23.3 \%)$ & $5(16.7 \%)$ & \\
\hline & Abandoned/ Lost follow up & $2(6.7 \%)$ & $3(10 \%)$ & \\
\hline
\end{tabular}

\begin{tabular}{|c|c|c|c|c|c|c|c|c|}
\hline \multirow[t]{2}{*}{ Group } & \multirow{2}{*}{$\begin{array}{l}\text { Intensity of Headache } \\
\text { (VAS) (D1-D7) Mean } \pm \text { SD }\end{array}$} & \multicolumn{2}{|c|}{$\begin{array}{l}95 \% \text { Confidence } \\
\text { interval for Means }\end{array}$} & \multicolumn{5}{|c|}{$\begin{array}{l}\text { One-way ANOVA for comparison between and } \\
\text { within groups. }\end{array}$} \\
\hline & & $\begin{array}{l}\text { Lower } \\
\text { Bound }\end{array}$ & $\begin{array}{l}\text { Upper } \\
\text { Bound }\end{array}$ & & $\begin{array}{l}\text { Sum of } \\
\text { Square }\end{array}$ & df & $\begin{array}{l}\text { Mean } \\
\text { square }\end{array}$ & $\mathrm{P}$ value \\
\hline $\begin{array}{l}\text { Perianal } \\
(\mathrm{n}=30)\end{array}$ & $3.30 \pm 2.5$ & 2.35 & 4.25 & $\begin{array}{l}\text { Between } \\
\text { group }\end{array}$ & 8.067 & 1 & 8.067 & 0.284 \\
\hline $\begin{array}{l}\text { Endoanal } \\
(\mathrm{n}=30)\end{array}$ & $2.57 \pm 2.7$ & 1.56 & 3.57 & Within group & 399.67 & 58 & 6.891 & \\
\hline
\end{tabular}

$d f=$ Degree of freedom; SD $=$ Standard deviation.

\section{DISCUSSION}

The anal fissure remains the one of the major presentation in surgical out-patient clinic and it is the common presentation in all age group but particularly more common in younger healthy people. The incidence is equal in both sexes. ${ }^{2}$ The fissure is usually located in the posterior midline but occurs anteriorly in approximately $20 \%$ of patients. The typical sfeature is pain during defecation which may last for 1-2 hour afterwards. ${ }^{11}$ This typical pain may be associated with varying degree of bleeding, perianal discomfort and growths called sentinel tag or pseudopolyp. Mostly, the symptoms of anal fissure cause significant morbidity and reduction in quality of life. ${ }^{3}$

According to presentation, they are either acute or chronic. Patients with acute anal fissures present with short history whereas chronic fissure are associated with long history of more than 6 weeks characterized by 
the presence of sentinel tag, heaped-up margin, fibers at base and or pseudo-polyps. Approximately $90 \%$ of acute anal fissures require only simple measures like laxative, topical anaesthetic, analgesics and sitz bath and heal spontaneously. But only a few of chronic anal fissures heal spontaneously without intervention whereas most do not. This is considered to be because of high resting anal tone due to internal anal sphincter spasm resulting local ischemia. The raised resting anal pressures reduce blood flow to anoderm by compressing blood vessels as the blood vessels pass through the hypertonic sphincter. ${ }^{12}$ Muscle spasm of the sphincter is in response to painful tear at muco-cutaneous junction. The treatment is mainly directed towards reduction of anal tone. This can be done by various means mainly surgical and chemical. ${ }^{2}$ Traditionally, the surgery was done by manual anal dilatation with "four finger stretch" or lateral anal sphincterotomy, a more controlled procedure. The Manual dilatation of the anus is a simple procedure which was previously a popular treatment. It is associated with higher rate of incontinence. The current opinion is that manual dilatation of the anus as a treatment of anal fissures is not recommended. The 'standard internal sphincterotomy' or lateral anal sphincterotomy comprises the division of only half of the internal anal sphincter to the dentate line in its lateral or posterolateral part. The aim of lateral sphincterotomy is to diminish internal anal sphincter tone and thereby to reduce the anal canal pressure. The result of which there is increase in anal mucosal blood flow which promotes the healing of anal fissures. Along with the associated risks and discomfort, surgery may cause incontinence. ${ }^{13}$ The other surgical technique like Anal advancement flap is done for the patients with primary or recurrent fissures specially in women with a complicated obstetric history. They have low resting anal canal pressure. The anal advancement flap technique avoids further disruption of the internal sphincter by this way avoids the factors that might otherwise jeopardize continence. ${ }^{14}$

Because of the complications associated with surgery, there has been preferences into the development of new pharmacological agents that causes relaxation of smooth muscle, lower resting anal pressure and promote healing of the chronic anal fissures. ${ }^{12,15}$ The tendency to treat this condition by medical means is to avoid the cost, time for recovery and risk of incontinence associated with surgery. ${ }^{5}$ Various pharmacological agents used are Organic nitrates, Calcium channel blockers, Botulinum toxin, alpha adrenoceptor agonist, beta adrenoceptor agonist and parasympathomimetics. The small scale results of the using alpha adrenoceptor agonist, beta adrenoceptor agonist and parasympathomimetics has been found to be good. The calcium channel blockers act by blocking slow L-type calcium channels in vascular smooth muscle to cause relaxation and vasodilatation. ${ }^{2}$ Farzaneh Gulfam et al have compared topical Nifedipine with Oral Nifedipine for the treatment of chronic anal fissure in a randomized controlled trial and found the superiority of topical application over the oral therapy. ${ }^{16}$ Botulinum toxin $A$, produced by Clostridium botulinum is a potent neurotoxin which binds to presynaptic cholinergic nerve terminal and inhibits the release of acetylcholine at the neuromuscular junction. It causes paralysis of muscle when injected at motor end plate zone of muscle, the effect remaining for 3-4 months until there has been axonal regeneration forming new nerve terminals. Injection in anal sphincter has lowered resting anal pressure and healed $82 \%$ of chronic anal fissures with few recurrences. Botulinum toxin injection is an invasive procedure and is associated with the complications like pain, sepsis and perianal hematoma. The exact site for injection whether in external and internal sphincter is also controversial which makes its role in the treatment of chronic anal fissure unclear. ${ }^{2,17,18}$ The topical GTN is the most frequently prescribed compound. ${ }^{19-21}$ GTN works as Nitric Oxide (NO) donor after being metabolized at a cellular level which mediates relaxation of the internal sphincter through the guanylyl cyclase pathway. The relaxation of internal sphincter reduces the ischaemia and enhances the healing of the fissure. ${ }^{2}$ There had been many modifications in the doses, combination and frequency of the treatment of GTN to increase the efficacy and reduction of its most common side effect of headache. We use $0.2 \%$ GTN ointment (Nitrogesic ${ }^{\circledR}$ ) available in our market. Most of the patients suffer from post application headache which varies in its intensity from mild to severe form for transient to long duration. Some have reported that in $20 \%-70 \%$ of patients and headache is incapacitating resulting withdrawal from treatment in approximately $10 \%$ of the patients. ${ }^{22-25}$ In our observation also, we found up to two-third of patients suffer from headache. Among which up to $10 \%$ were having severe headache. The substantial work done by many has shown limitation of topical agents because of its side effects and lower rate of healing in comparison to surgery. Libertiny et $\mathrm{al}^{26}$ in a comparative trial between surgery and phamarcological agents showed $98 \%$ healing of anal fissure with lateral internal sphincterotomy while GTN relieved $56 \%$, with $10 \%$ recurrence. Other similar studies Simpson et al, ${ }^{27}$ Lysy $\mathrm{J}$ et al, ${ }^{28}$ Novell $\mathrm{F}$ et al, ${ }^{29}$ show fissure healing in $66.7 \%$ with side effect of headache and a recurrence rate of $25 \%$ within six months of topical GTN. Despite the improvements in the surgical techniques and wide spread use of pharmacological preparations, treatment of chronic anal fissure still remains to be a clinical problem in patients who are unfit for surgery such as patients with severe neutropenia, hematological disorders, hepatitis, HIV, and some malignancies. ${ }^{30}$ 
Surgery is associated with surgery related complication whereas pharmacological preparation are associated with headache and lower rate of healing as well as the recurrences.

Torrabadella and Salgado, in a study has compared endoanal with perianal application of $0.3 \%$ nitroglycerine ointment and found to have headache in 1 of 10 patients of endoanal group and 10 in 12 of perianal group. The degree of anal pain relief was similar in both group. ${ }^{10}$

Several theories have been given to explain the reduction of incidence of headache in endoanal group. First, as there are three mechanisms for ointment absorption transcellular, intercellular and appendageal absorption. As the perianal skin in rich in appendages there might be more ointment absorption than endoanal site and the sebaceous glands may act as a drug reservoir for some material. ${ }^{31}$ Second, thin keratinized anoderm allows more and rapid absorption of the drug and uncovered fingertip may also allow absorption of some amount of drug. ${ }^{10}$ Thirdly, Glyceryl trinitrate is rapidly metabolized by liver by hepatic enzymes. So in endoanal group area above dentate line are drained in to portal circulation where as in perianal group it is systemically absorbed which may be the cause for the more headache in perianal group. ${ }^{32}$

Patient parameters in two group were of almost similar in regards to age group. Female ratio in higher in endoanal group, although the difference is not significant. Mode of presentation is also similar, Whereas the duration of pre-treatment symptoms is different in between two groups. (Table 1). We have observed and followed up the patient for 6 weeks. During this period, complete healing was more in perianal group than in endoanal whereas partial healing is more in endoanal group. But overall healing was seen in approximately $70 \%$ of individuals in either group which is good response and if observed for longer both the group, we assume, will have similar rate of healing. The duration of chronicity, which is different in both the groups, did not show any impact in overall outcome. Incidence and severity of headache which is our main aim of study is shown in table 2 and 3 . Unlike the observation of Torrabadella et al, we did not find the advantage of endoanal therapy for lowering the incidence and severity of headache statistically although mean severity score is slightly lower in endoanal group (Table 3). There is always some form of individual variation in mode the therapy applied and bias in record keeping when the patients are treated as an outpatient basis. We think there might have been some difficulty in endoanal application of ointment because proper applicator was not available in many instances. If the application of ointment is not proper, the endoanal ointment becomes perianal as it remains below dentate line and the theoretical advantages mentioned above do not apply. All patient in our group applied the ointment without using the gloves. This could be the reason of slight higher incidence of headache in our study as it is said that naked fingertip allows absorption of more GTN to the circulation.

Limitations: The study was carried out as an outpatient basis, there might be individual variation according to patient's level of understanding regarding the ointment application and record keeping of VAS scale. The other factors associated to influence the incidence of headache were not taken into consideration. We have not recorded the incidence of symptomatic relief of fissure pain with the application to GTN in between two groups which is one of the important outcome variable. Our observation was for limited time, we could not evaluate the recurrence.

\section{CONCLUSIONS}

Both the perianal and endoanal application of GTN are comparable in terms of fissure healing and overall outcome of patient. The incidence of headache is slightly lower in endoanal group than perianal. The larger scale further evaluation is needed to see the advantage of this modality of therapy.

\section{ACKNOWLEDGEMENTS}

We like acknowledge all the members in the department of surgery, outpatient clinic attendant and Statistician Dr. Naresh Manandhar for support and guidance.

\section{Conflict of Interest: None.}

\section{REFERENCES}

1. Golligher JC. Surgery of the anus, rectum and colon. $3^{\text {rd }}$ ed. London, Balliere and Tindall 1975.

2. Jonas M, Scholfield JH. Anal Fissure. Gastroenterol clin North Am. 2001 March;30(1):167-81.

3. Sailer M, Bussen D, Debus ES, Fuchs KH, Thiede A. Quality of life in patients with benigh anorectal disorders. Br J Surg.1998 Dec; 85(12):1716-9.

4. Schouten WR, Briel JW, Auwerda JJ. Relationship between anal pressure and anodermal blood flow.The vascular pathogenesis of anal fissures. Dis. Colon Rectum. 1994 Jul;37:664-9.

5. Nelson R. A systemic review of medical therapy for anal fissure. Dis Colon and Rectum. 2004 Apr;47(4):422-31. 
Joshi et al. Comparison of Fissure Healing and The Incidence of Headache Among the Patients Treated with Endo- and Perianal ...

6. Madoff RD. Pharmocologic therapy for anal fissure. N Eng J Med. 1998;338(4);257-9.

7. Lund JN, Scholefield JH. A randomised, prospective, double-blind , placebo-controlled trial of glyceryl trinitrate ointment in treatment of anal fissure. Lancet. 1997Jan;349(9044):11-4.

8. O' kellyTJ. Nerves that say NO: a new perspective on the human rectoanal inhibitory reflex. Ann R Coll Surg Engl. 1996 Jan;78(1):31-8.

9. Scholefield JH, Bock JU, Marla B, Richter HJ, Athanasiadis S, Prols $\mathrm{M}$ et al. A dose finding stydy with $0.1 \%, 0.2 \%$, and $0.4 \%$ glyceryl trinitrate ointment in patients with chronic anal fissures. Gut. 2003 Feb;52(2):264-9.

10. Torrabadella L, Salgado G. Controlled dose delivery in topical treatment of anal fissure: pilot study of a new paradigm. Dis Colon Rectum. 2006 Jun;49(6):865-8.

11. Lindsey I, Jones OM, Cunningham C, Mortensen NJ. Chronic anal fissure. Br J Surg. 2004 Jun;91(3):270-9.

12. Acheson AG, Scholefield JH. Anal fissure: The changing management of a surgical condition. Lagenbecks. Arch Surg. 2005 Feb;390(1): 1-7.

13. Mishra R, Thomas S, Maan MS, Hadke NS. Topical nitroglyerin versus lateral internal sphincterotomy for chronic anal fissure: prospective, randomized trial. ANZ J Surg. 2005 Dec;75(75):1032-1035.

14. Zubaeri BF, Baloch $\mathrm{Q}$, Abro H. Glyceryltrinitrate ointment in the treatment of anal fissures. J Coll Physicians Surg Pak. 1999;9:410-2.

15. Mentes BB, Irkorucu O, Akin M, Leventoglu S, Tatlicioglu E. Comparison of botulinum toxin injection and lateral internal sphincterotomy for the treatment of chronic anal fissure. Dis Colon Rectum 2003 Feb; 46(2):232- 7.

16. Golfam F, Golfam P, Golfam B, Pahlevani P. Comparison of topical nifedipine for treatment of anal fissure: a randomized controlled trial. Iran Red Crescent Med J. 2014 Aug;16(8):1-3. e13592. doi: 10.5812/ircmj.13592. Epub 2014 Aug 5

17. Gui D, Cassetta E, Anastosio G, Bentivoglio AR, Maria G, Albanese A. Botulinum toxin for chronic anal fissure. Lancet 1994 Oct;344(8930):1127-8.

18. Jost WH. One hundred cases of anal fissure treated with botulin toxin: early and long-term results. Dis Colon Rectum.1997(Sep);40(9): 1029-32.
19. Lund JN, Nystrom PO, Coremans G, Herold A, Karaitinos I, Spyrou $\mathrm{M}$ et al. An evidence-based treatment algorithm for anal fissure. Tech Coloproctol. 2006 Oct;10(3):177-80.

20. Madoff RD, Fleshman JW. AGA technical review on diagnosis and care of patients with anal fissure. Gastroenterology. 2003 Jan;124(1):235-45.

21. Lubowski D. Topical therapy is first line treatment for chronic anal fissure because of the risk of incontinence with sphincterotomy. Dis Colon rectum. 2008 Jul;51(7):1157-8.

22. Gagliardi G, Pascariello A, Altomare DF, Arcana F, Cafaro D, La Torre F et al. Optimal treatment duration of glyceryl trinitrate for chronic anal fissure : results a prospective randomized multicenter trial. Tech coloproctol.2010 Sep;14(3):241-8.

23. Azarnoff DL, Lee JC, Lee C, Chandler J, Karlin D. Quality of extemporaneously compounded nitroglycerin ointment. Dis Colon Recutm. 2007 Apr;50(4):509-16.

24. Sands LR. $0.4 \%$ nitroglycerin ointment in the treatment of chronic anal fissure pain: a viewpoint by Laurence R. Sands. Drugs. 2006;66(3): 350-2.

25. Nash G. GTN headache and reduction of natural banding? Colorectal Dis. 2008 Jan;10(1):96.

26. Libertiny G, Knight JS, Farour R. Randomized trial of topical $0.2 \%$ glyceryltrinitrate and lateral internal sphincterotomy for the treatment of patients with chronic and fissure: longterm follow-up. Eur J Surg. 2002;168(7):418-21.

27. Simpson J, Lund JN, Thompson RJ, Kapila L, Schlefield JH. The use of GTN in the treatment of chronic anal fissure in children. Med Sci Monit. 2003 Oct;9(10):123-6.

28. Lysy J, Israeli E, Levy S, Rozentzweig G, Strauss- Liviatan N, Goldin E. Long-term results of chemical sphincterotomy for chronic anal fissure: a prospective study. Dis Colon Rectum. 2006 Jun;49(6):858-64.

29. Novell F, Novell-Costa F, Novell J. Topical glyceryltrinitrate in the treatment of anal fissure. Rev Esp Enferm Dig. 2004 Apr;96(4):255-8.

30. North JH Jr, Weber TK, Rodriquez-Bigas MA, Meropol NJ, Petrelli NJ. The management of infectious and noninfectious anorectal complications in patients with leukemia. J Am Coll Surg. 1996 Oct;183(4): 322-8.

31. Keilhorn J, Melching-Kollmu $\beta$ S, Mangelsdorf I. Dermal Absorption: World Health Organization: 2006.

32. Godlewski G, Prudhomme M. Embryology and anatomy of the anorectum. Basis of surgery. Surg Clin North Am. 2000 Feb;80(1):319-43. 